University of Nebraska - Lincoln

DigitalCommons@University of Nebraska - Lincoln

\title{
Quality and Agronomic Effects of Three High-Molecular-Weight Glutenin Subunit Transgenic Events in Winter Wheat
}

\author{
Robert A. Graybosch \\ USDA-ARS; University of Nebraska-Lincoln, bob.graybosch@ars.usda.gov \\ Bradford Seabourn \\ USDA-ARS \\ Yuanhong R. Chen \\ USDA-ARS
}

Ann E. Blechl

USDA-ARS

Follow this and additional works at: https://digitalcommons.unl.edu/usdaarsfacpub

Part of the Agricultural Science Commons

\footnotetext{
Graybosch, Robert A.; Seabourn, Bradford; Chen, Yuanhong R.; and Blechl, Ann E., "Quality and Agronomic Effects of Three High-Molecular-Weight Glutenin Subunit Transgenic Events in Winter Wheat" (2011). Publications from USDA-ARS / UNL Faculty. 905.

https://digitalcommons.unl.edu/usdaarsfacpub/905
}

This Article is brought to you for free and open access by the U.S. Department of Agriculture: Agricultural Research Service, Lincoln, Nebraska at DigitalCommons@University of Nebraska - Lincoln. It has been accepted for inclusion in Publications from USDA-ARS / UNL Faculty by an authorized administrator of DigitalCommons@University of Nebraska - Lincoln. 


\title{
Quality and Agronomic Effects of Three High-Molecular-Weight Glutenin Subunit Transgenic Events in Winter Wheat ${ }^{1}$
}

\author{
Robert A. Graybosch, ${ }^{2.3}$ Bradford Seabourn, ${ }^{4}$ Yuanhong R. Chen, ${ }^{+}$and Ann E. Blechl ${ }^{5}$
}

\section{ABSTRACT}

Cereal Chem. 88(1):95-102

\begin{abstract}
Quality and agronomic effects of three transgenic high molecular weight glutenin subunit (HMW-GS) events were characterized in advancedgeneration breeding lines of hard winter wheat (Triticum aestivam $\mathrm{L}$.) in three Nebraska crop years. Two of the transqenic events studied. Dy 10-E and B52a-6, overexpress HMW-GS IDyl0, while the third event. Dx5 +Dy 10-H, overexpresses HMW-GS 1Dx5 and, to a much lesser extent, 1Dyl0. In addition, novel proteins possessing solubility characteristics delined as HMW-GS were presen in Dx5+Dy10-H and B52a-6. Average grain yield of lines derived from the three transgenic events was statistically lower than that of a group of control cultivars and advanced breed-
\end{abstract}

ing lines, but not lower than the mean values of respective nontransgenic siblings. Grain hardness was influenced by one of the events. Dx5+Dy 10-H produced harder kernels than controls, its nontransgenic siblings, and the two additional transgenic events. All three events produced doughs with unusual mixing properties, although not likely to be directly useful in commercial applications. As a consequence, loaf volumes were depressed to variable degrees by the three events. The results indicated that overexpression of HMW-GS could eventually lead to improved breadmaking quality by optimizing the level of overexpression or by development and characterization of additional events.
Efficient and reproducible techniques for the genetic transformation of wheat (Triticum aestivum L.) have been available for many years (Vasil et al 1992; Weeks et al 1993). Initial efforts concentrated on the introduction of additional copies of genes encoding high molecular weight glutenin subunits (HMW-GS). These proteins are associated with, and predictive of, wheat enduse processing. especially dough strength and breadmaking quality (reviewed by Payne 1987; Shewry et al 1994; Weegels et al 1996). Therefore. strategies to incorporate additional copies of specific subunits to enhance their expression seemed a most logical application of novel techniques of genetic manipulation. Altpeter et al (1996) and Vasil et al (2001) demonstrated that wheat lines could be transformed with, and express, additional copies of HMW-GS $1 \mathrm{Axl}$, and that glutenin content of the recipient wheat lines was increased. Vasil et al (2001) also suggested breadmaking quality could be improved, though their investigation used samples from only one location and growing season. Blechl and Anderson (1996) transformed wheat to synthesize a chimeric glutenin protein, produced by fusing DNA sequences of the genes producing HMW-GS 1Dy10 and 1Dx5. Shimoni et al (1997) found that this chimeric protein often remained in monomeric form, acting more as a monomeric gliadin than as a glutenin subunit and rarely polymerized. They attributed this behavior to an unusual disulfide bond linking an $\mathrm{N}$-terminal cysteine residue to a $\mathrm{C}$-terminal residue. This intramolecular bond tended to form and block the incorporation of the molecule into glutenin polymers. As a consequence, dough strength actually was reduced (Blechl et al 1997).

Most additional experiments designed to elevate expression of HMW-GS have resulted in increases in dough strength, though at times the increases have been too dramatic for practical applications. Barro et al (1997) found that transformation of lines to overexpress HMW-GS subunits $1 \mathrm{Ax} 1$, 1Dx, or the two in combination resulted in increased mixograph times and tolerance to overmixing. Darlington et al (2003) found that overexpression of

\footnotetext{
I Joint contribution of the United States Department of Agriculture, Agricultural Research Service and the Department of Agronony and Horticulture, University of Nebraska-Lincoln. Mention of tirm names or trade products does not imply that they are endorsed or recommended by the USDA or the University of Nebraska over other firms or producls not mentioned.

2 ISSDA-ARS, 137 Keim Hall, East Campus, University of Nebraska, Lincoln, NE.

'Corresponding author. Email: bob.graybosch $($ ars. usda.gov

${ }^{4}$ USDA-ARS. Hand Winter Wheat Quality Laboratory, Manhattan, KS.

${ }^{5}$ USDA-ARS. Western Regional Research Center, Albany, CA.
}

doi:10.1094/CCHEM-08-10-0121

This article is in the public domain and not copyrightable. It may be freely reprinted with customary crediting of the source. AACC International, Inc., 2011.
$1 \mathrm{D} \times 5$ resulted in loaves with depressed volumes, poor crumb appearance; overexpression of 1 AxI essentially did no damage, but no obvious improvements were evident. Blechl et al (2007) examined 13 transformation events resulting in overexpression of subunits 1Dx5, IDx10, or both in concert. Levels of polymeric protein in transgenic flours increased dramatically. Flours with levels of $1 \mathrm{D} \times 5>2.6 \times$ native amounts could not be mixed in a $2-\mathrm{g}$ mixograph (e.g. mixograph curves never reached well-defined peaks) under standard conditions. Flours with $\leq 5.4 \times$ native amounts of IDy 10, however, could be mixed to peak, though peak times were far longer than typically observed with nontransformed wheats. In combination, overexpression of 1 Dx 5 and 1 Dy 10 resulted in additive effects (Blechl et al 2007). Masci et al (2003) extended observations to the low-molecular weight glutenin subunits (LMWGS), overexpressing one such gene in a transgenic "Bobwhite" background. SDS sedimentation volumes of expressing lines actually were suppressed, even though protein and glutenin concentrations were increased. Leon et al (2009) achieved greater success in improving poor quality wheats to useable levels. Through intermatings of transgenic parental lines, they combined genes overexpressing HMW-GS $1 \mathrm{Ax} 1,1 \mathrm{D} \times 5$, and $1 \mathrm{Dy} 10$. and found they could increase mixograph mixing times of the parental wheat 'Anza' from an unacceptably low level of 0.5 min up to a commercially acceptable value of 3.0 min. Field et al (2008) obtained similar results, though they found introgression of extra copies of the $1 D x 5$ gene resulted in an overstrong. "bucky" dough, while extra copies of IAxI provided commercially acceptable levels of dough strength. Nearly identical results were reported by Rakszegi et al $(2005,2008)$ and Wang et al (2010).

Some of the transgenic lines of the experiments reported herein were used previously (Pierucci et al 2009) to study the effects of HMW-GS overexpression on tortilla properties. Transgenic lines derived from initial transformation events Dy $10-E$ and B52a-6, were compared to nonexpressing (nontransgenic) sibling lines to investigate the effects of overexpression of HMW-GS IDy 10 . Levels of subunit 1Dy 10 were elevated $2.5-5.8$ fold in the transgenic lines. Mixograph mixing times of lines derived from Dy $10-\mathrm{E}$ exceeded $40 \mathrm{~min}$ (3-4 min is considered optimal in Great Plains breeding programs) (USDA 2006). In lines derived from B52a-6, mixograph mixing times of $\approx 20$ min were observed, as opposed to $3-5$ min for nontransgenic siblings. Marked increases in polymeric protein concentrations were observed in Dyl0-E lines, with less pronounced elevation in B52a-6 lines; polymer concentrations generally were proportional to increases in mixing times. Dough derived from both sets of transgenic wheats had greater resistance to extension and lower extensibility than the control samples. 
Tortillas produced from transgenic wheats also displayed decreased diameter, greater thickness and rupture force, and lower rollability scores and stretchability.

Agronomic evaluations of HMW-GS transgenic lines have been reported. Barro et al (2002) evaluated four transgenic HMW-GS lines under field conditions, found no significant differences in grain yicld attributable to the presence of any particular transgene, but did note differences in heading dates among transgenic genotypes. Shewry et al (2006) evaluated field performance of three of the same transgenic HMW-GS lines over three years and two sites and found no reduction in grain yield with stable performance over years. Bregitzer et al (2006) studied the field responses of 50 transgenic lines of Bobwhite carrying one or two of nine different HMW-GS constructs and compared them to both nontransgenic sibling lines and parental controls. A wide range of response in grain yield was observed, though most transgenic lines were not significantly different from the Bobwhite parental control. Significant yield reductions at all locations were observed for five transgenic lines. Nontransgenic sibling lines had the same yields as the nontransformed parent. Thus, the low yields in some transgenic lines were probably not due to pleiotropic effects resulting from tissue-culture induced somaclonal variation, but rather to the insertion site or structure of certain transformation events.

Many proteomic evaluations of transgenic plants have demonstrated qualitative. but not necessarily quantitative, equivalence of protein compositions of transgenic and control plants (Ruebelt et al 2006; Scossa et al 2008). However, genetic transformation of plants can result in gene silencing, rearrangements. changes in gene expression, or the production of novel and at times, unexpected proteins (Mehlo et al 2000; Altpeter et al 2005) particularly when HMW-GS genes are transformed into wheat (Altpeter et al 1996; Barro et al 1997. Alvarez et al 2000. He et al 2005. Blechl et al 2007). Di Luccia et al (2005) found novel proteins produced in transgenic durum ( $T$. turgidum L, var durum (Desf.) Bowden) wheat engineered to alter trafticking of gluten proteins. A novel $\beta$ amylase was identified, along with unidentified trypsin-insensitive proteins. Chen et al (2009) detected both quantitative and qualitative changes in the proteome of seeds of transgenic peas (Pisum sativum L.) expressing $\alpha$-amylase inhibitor-1 from Phaseolus vilgaris $\mathrm{L}$, though the identity of novel proteins found in the transgenic lines was not reported. Giuliano Albo et al (2007) detected unique proteins identified as glucose dehydrogenase and endochitinase $A$ in transgenic maize. Little is known of the phenotypic effects of novel or unexpected protein production in transgenic plants.

Previous investigations with transgenic HMW-GS provided limited quality data and often lacked final product information. In addition, with the exception of investigations on the chimeric HMW-GS introduced by Blechl and Anderson (1996), all previous studies concentrated on the effects of overexpression of native HMW-GS. The goals of the present investigation included comprehensive quality evaluation of breeding lines derived from three transformation events. Two of the constructs investigated resulted in the production of novel HMW-GS, presumably by accidental gene rearrangements during the process of insertion of exogenous DNA into the wheat genome. Rather than vicw these novel HMW-GS as detrimental, experiments were conducted to determine whether such novel genes and protein products provide useful genetic variation.

\section{MATERIALS AND METHODS}

\section{Plant Materials}

Development of the transgenic lines and nontransgenic sibling lines from events Dy 10-E and B52a-6 was described by Pierucci et al (2009). In addition, lines were developed from event Dx.5+ Dy 10-H. Dx5+Dy 10-H was produced in the same experiment that generated the "Dx5 + Dy 10" lines described in Blechl et al (2007) after transformation with separate constructs containing promoter, coding, and terminating sequences from genes encoding HMWGS 1Dy 10 and 1Dx5. Phenotypically, Dx5+ Dy 10-H highly overexpresses HMW subunit 5; overexpression of subunit 10 is slight. In addition, a novel protein, migrating at an apparent $M W$ greater than that of native HMW glutenin subunit $1 \mathrm{~A} \times 2^{*}$, is produced. Dy $10-$ E overexpresses HMW-GS 1Dyl0. B52a-6 also was transformed to overexpress HMW-GS 10 using the same promoter, coding. and terminating sequences as used to develop Dy I0-E. In addition, B $52 \mathrm{a}-6$ also produces two novel proteins, migrating in the zone between native wheat HMW-GS 1 Dx 5 and $1 B y 7$ when glutenin subunits are separated by SDS-PAGE. The identities of these proteins have not been determined, though the proteins possess the solubility properties of HMW-GS.

Breeding procedures and generation advances were described previously (Pierucci et al 2009). Pedigrees are written as in Purdy et al (1968). Based on overexpression of HMW-GS, putative transgenic lines were identified among lines derived from the following breeding populations: Population $1=$ Dy $10 \mathrm{E} / \mathrm{W} 96-495 \mathrm{~W} / \mathrm{I}$ N86L 177; 2 = Dx5+Dy 10-H/ 'Jagger'//KS85W663-1-1/'Karl 92": $3=$ DY 10 E/N97S286//'TAM202 $; 4$ = B52a-6/Jagger $/ /{ }^{\prime}$ Heyne'; 5 = B52a-6/Jagger $/{ }^{-B}$ Betty'. In fall 2003, lines were seeded in unreplicated $5 \mathrm{~m}^{2}$ plots at Mead, NE. Plots were trimmed to $2.9 \mathrm{~m}^{2}$ before harvest.

Nontransgenic commercial cultivars 'Anton', 'Trego', Karl 92, Jagger, and 'Nuplains', and the advanced breeding lines NW99 L7068, N86L177, and NP-02 were seeded as controls along with the experimental materials. Some transgenic and nontransgenic lines were lost due to inadequate winter-hardiness for Nebraska conditions. A total of 15 homozygous, homogeneous, winterhardy transgenic lines were recovered. Eight of the transgenic lines were derived from event Dyl(0-E, three were derived from event Dx5+Dy $10-\mathrm{H}$, and four arose from event B52a-6. In fall 2004, the transgenic lines, along with 19 nontransgenic sibling lines (minimum of four/event), and the control lines cited above were seeded in a three-replicate randomized complete block design, again at Mead, NE. Plot size at harvest was $8 \mathrm{~m}^{2}$. The study was replanted at Mead. NE, in fall 2005 and 2006. again using threereplicate randomized complete block designs. Transgene expression was monitored by SDS-PAGE evaluations after the 2006 and 2007 harvests.

\section{Agronomic and Quality Analyses}

Grain yield and grain volume weight were measured by typical agronomic procedures. Kernel weight and hardness scores were obtained from an average of 300 kernels/sample using the single kernel characterization system (SKCS, Perten Instruments, Springfield. IL). Wheat samples were tempered to $15 \%$ moisture content for $>16 \mathrm{hr}$ before milling on an experimental Quadrumat Sr. mill (C.W. Brabender Instruments, South Hackensack, NJ) for production of break flour, reduction flour, bran, and shorts. A straightgrade flour produced by blending break and the reduction flours together was used for all quality analyses and evaluations. Grain and flour protein were measured by near-infrared reflectance spectroscopy using Approved Methods (AACC International 2010). Mixograph mixing time $(\mathrm{min})$, mixograph tolerance score (0-6 scale, with $0=$ unacceptable), farinograph peak time (min), farinograph stability (min), farinograph mixing tolerance index (BU), bake flour water absorption (\%), and loaf volume $(\mathrm{mL})$ were assessed using AACC Approved Methods. Mixograph times and tolerances proved difficult to assess in samples of lines derived from Dy $10-E$ and Dx5+Dy $10-\mathrm{H}$. Well-defined mixing peaks often were not detected.

When peak times were absent, mixographs were classified as unscored. Quality analyses were conducted independently for each of the three field replicates from each harvest year. For the sake of brevity, not all of the quality analyses conducted will be reported. 


\section{Statistical Analyses}

Software for PC was used for all computations (v.9.1. SAS Institute, Cary, NC). Proc GLM was used to conduct analysis of variance of the main effects: year, replicate within year. treatment, and the year-by-treatment interaction. Seven treatments were identified: controls, three transgenic events, and groups of nontransgenic sibling lines of each transgenic event. For purposes of this study, controls were the winter wheat cultivars and advanced breeding lines and were included as a means of comparing responses of transgenic lines to those expected among current winter wheat germplasm pools. Mean values for each treatment computed over years and replicates were compared by single degree of freedom contrasts. Contrasts were used to compare mean responses of 1) each transgenic event to the controls, 2) transgenic events to each other, and 3 ) transgenic events to respective nontransgenic sibling lines. To compare and assess variability of responses over time, coefficients of variation $(\mathrm{CV})$ were calculated. The frequency of unscored mixographs was determined for each treatment. Chisquare $\left(X^{2}\right)$ analysis was used to determine whether observed frequencies (expressed as fractions) differed from the expected frequency of 1.0 (well-defined peaks always observed, as in the controls). Treatments with statistically significant $X^{2}$ values were excluded from calculation of contrasts for mixograph times and tolerances.

\section{RESULTS AND DISCUSSION}

SDS-PAGE separation of samples from the 2006 harvest year clearly revealed overexpressed HMW-GS in transgenic lines and the absence in nonexpressing (nontransgenic) sibling lines and controls (Fig. 1). Overexpression of 1 Dy 10 was evident in B52a-6 and Dy $10-E$ derivatives, but this subunit was only slightly overexpressed in Dx5+Dy $10-\mathrm{H}$ lines. In contrast, HMW-GS 1Dx5 was markedly overexpressed in Dx $5+$ Dy $10-\mathrm{H}$ derivatives. In addition, novel HMW-GS were evident in samples derived from transformation events B52a-6 and Dx5+Dy 10-H. The novel HMW-GS in B52a- 6 derivatives separated as a doublet in the region between HMW-GS 1 Dx5 and 1Bx7. The novel HMW-GS in Dx5+Dy l0-H derivatives migrated with an apparent MW greater than that of HMW-GS $1 \mathrm{Ax} 1$. Mass spectrometry has determined that the latter band is a variant of HMW-GS 1Dx5 (A. E. Blechl, personal (communication).

Analysis of variance (not shown) revealed significant variation for all traits for year and treatment, and for all interactions between treatments and years. Contrasts (Table I) showed that average grain yields of all three transgenic treatments were statistically lower than the mean of the controls. The average grain yield of Dy $10-E$ lines exceeded that of nontransgenic siblings; no statistically significant contrasts were observed for the comparison of the two additional transgenic events and the respective siblings. In addition, the average grain yield of both Dy10-E and B52-a6 exceeded that of Dx5+Dyl0-H lines. The lower grain yield of the transgenic lines, relative to the controls, therefore. was not due to transformation per se. If so, lower yields would have also been observed relative to the nontransgenic siblings. Transgenic materials were derived only by two rounds of crossing to adapted winter wheats and they still carry significant amounts of genetic material from the parental Bobwhite line, which is a spring wheat unadapted to Great Plains winter wheat environments. Two rounds of crossing would be considered a minimal number of matings in breeding programs using unadapted parents as sources of useful genes. Continued introgression of transgenes to adapted backgrounds very likely will result in lines with grain yields consistently competitive with commonly grown cultivars. All transgenic and nontransgenic groups displayed greater variability in grain yield over years, shown by higher $\mathrm{CV}$ than controls (Table I). A negative effect of transformation was observed on grain volume weight. All three transgenic events had average grain volume weights lower than both controls and the respective transgenic siblings (Table I). However, two events (Dy $10-\mathrm{E}$ and Dx5+Dy 10-H) had higher average single kernel weights than the controls, while the mean of B52-a6 lines did not differ from controls. Controls may have produced more, albeit smaller kernels per $\mathrm{m}^{2}$ in the field. For grain hardness, a distinct effect of one transgenic event was observed (Table 1). Dx5+Dy10-H produced harder kernels than controls, its nontransgenic sibling lines, and both additional transgenic events. Dy 10-E produced harder kernels than those of its nontransgenic sibling lines, but not harder than those of the controls or B52a-6 derived lines. While grain hardness generally is attributed to effects of puroindolines (Greenwell and Scofield 1986) and associated membrane-derived lipids (Finnie et al 2010), it is a physical manifestation of the interaction of the protein matrix and starch granules and gluten protein aggregation also influences this interaction (Stenvert and Kingswood 1977). The gluten produced by Dx5+Dy1()-H lines might have resulted in a tighter gluten matrix or a firmer connection of the matrix to the starch granules.

Mean grain protein concentrations of the three transgenic treatments were all statistically higher than that of the controls but not different from each other nor from the respective nontransgenic siblings (Table I). The higher grain protein relative to the controls could be merely a consequence of the lower grain yield. Higher grain protein does not explain elevated hardness of Dx $5+$ Dy $10-\mathrm{H}$ lines because an effect on hardness was not noted in the two additional transgenic treatments. Flour protein concentrations demonstrated the same response as the grain protein concentrations (Table II).

Flour extraction percentage after milling of transgenic treatment Dx $5+$ Dy $10-\mathrm{H}$ was significantly lower than the controls and the nontransgenic siblings, while that of the B52a-6 treatment was only lower than the controls. Flour ash concentrations of Dx5+ Dy $10-\mathrm{H}$ and Dyl0-E were higher than the controls and all the transgenic treatments had higher ash contents than nontransgenic siblings. The lower extraction and higher ash of Dx $5+$ Dy $10-\mathrm{H}$ could be a consequence of greater grain hardness; however, a

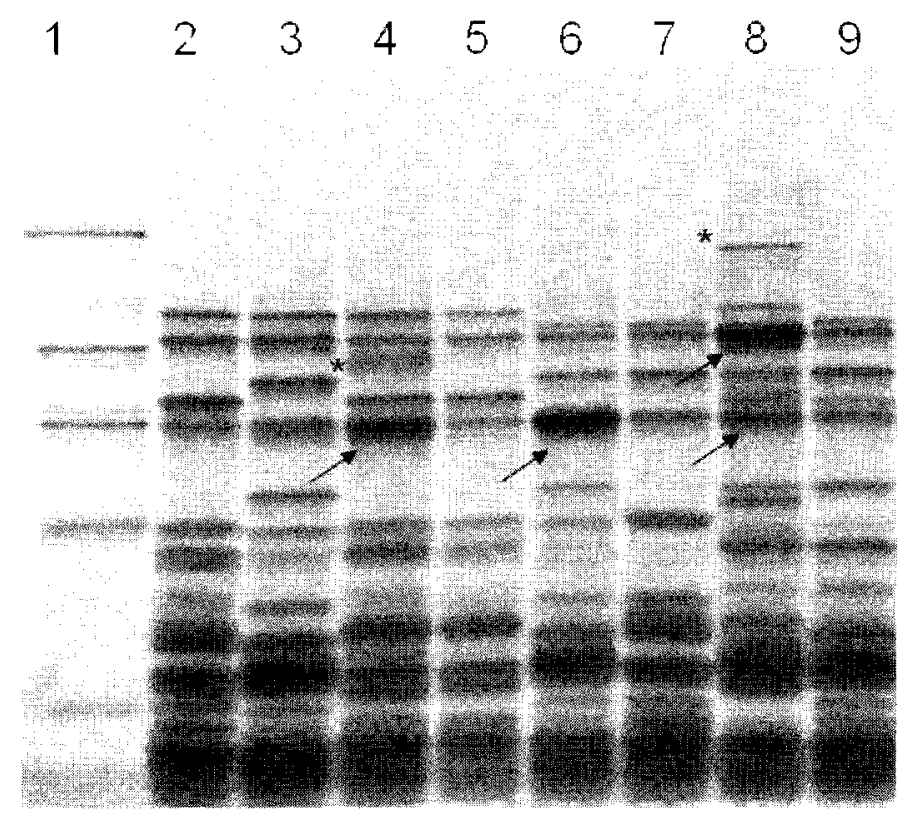

Fig. 1. SDS-PAGE separation of total proteins from controls. transgenic lines. and nontransgenic sibling lines. Lane $1=$ markers, 2 = Jagger, $3=$ N86L 177, $4=$ N04MD2069 (B52a-6). $5=$ N04MD2078 (nontransgenic), $6=\mathrm{N} 04 \mathrm{MD} 2050(\mathrm{Dy} 10-\mathrm{E}) .7=\mathrm{N}(04 \mathrm{MD} 2065$ (nontransgenic $) .8=\mathrm{N}(4) 4 \mathrm{MD}$ 2109 (Dx5+Dy $10-\mathrm{H}-\mathrm{H}) .9=\mathrm{N} 04 \mathrm{MD} 2090$ (nontransgenic). Arrows designate overexpressed HMW glutenin subunits: "* designate novel HMW glutenins arising from rearranged genes. 
similar association with hardness was not noted in the two additional transgenic treatments.

Figure 2 documents the dramatic nature of changes in mixograph properties from the transformation events. Mean mixograph times of the controls ranged from $3 \mathrm{~min}$ (Trego, Fig. 2A) to $6 \mathrm{~min}$ (Anton, Fig. 2B) with an overall control mean value of $4.3 \mathrm{~min}$. In successive panels of Fig. 2, representative mixograms of the three transgenic events (right) are paired in the same row with representative mixograms from nontransgenic siblings (lef1). The three transgenic treatments characterized resulted in different mixograph responses (Table II, Figure 2). All transgenic lines derived from Dy $10-E$ exhibited what might be considered an "extra strong" mixing phenotype with a mean mixing of $40+\min$; in contrast, nontransgenic siblings for this treatment had a mean mixograph time of 9.2 min (Fig. 2D vs. C). Several samples of this treatment displayed mixograms lacking well-defined peaks. The frequency of such samples, however, was not statistically different from 1.0 $\left(X^{2}=0.041, P>0.05\right)$. Hence, contrasts were calculated to compare results to additional treatments. In contrast, the frequency of samples of lines derived from Dx5+Dy $10-\mathrm{H}$ lacking well-defined mixing peaks differed from $1.0\left(X^{2}=0.502, P<0.05\right)$. Therefore, statistical contrasts comparing Dx5+Dyl0-H to other treatments were not calculated. Such samples exhibited long, flat mixograph curves, lacking well-defined peaks (Fig. 2F). Blechl et at (2007) observed a similar effect, with lines overexpressing HMW-GS 5 producing long, narrow mix curves that often failed to peak and lines overexpressing HMW-GS 10 also displaying long curves that eventually did reach a peak resistance. In B52a-6 materials, mean mixograph mixing times of the transgenic lines were $\approx 4 \times$ as long as both the controls and the nontransgenic siblings (Table II: Fig. $2 \mathrm{G}$ and $\mathrm{H}$ ). Mixing times were long, but well-defined peaks eventually were discerned. Mixograph peak times of Dyl0-E and B52a-6 differed significantly from the controls, the respective nontransgenic siblings. and from each other (Table II).

The degree of glutenin polymerization in native wheat, accomplished by the formation of intermolecular disulfide bond formation, increases in a linear manner during grain ripening (Wrigley et al 2006). During dough mixing, disultide bonds break and reform, additional disulfide bonds are established, and flour particles, composed of starch and protein, absorb water (Wrigley et al 2006). It is possible that the number of disulfide bonds formed during grain maturation in transgenic HMW-GS lines, especially

TABLE I

Mean Values and Statistical Contrasts for Grain Traits, Transgenic Lines (T), Nontransgenic Siblings (N), and Control Cultivars, 2005-2007, Mead, NE

\begin{tabular}{|c|c|c|c|c|c|c|}
\hline \multirow[b]{2}{*}{ Treatment } & \multirow[b]{2}{*}{ Grain yield ( $\mathrm{kg} / \mathrm{ha}$ ) } & \multicolumn{5}{|c|}{ Contrasts $^{a}$} \\
\hline & & $\mathrm{CV}(\%)$ & Controls & Nontransgenic Siblings & Dx5+Dy 10-H T & B52a-6 T \\
\hline Controls & 5071 & 20 & & & & \\
\hline Dy I0E N & 3604 & 50 & & & & \\
\hline DyloE T & 4031 & 34 & $<0.0001$ & 0.0152 & 0.0097 & 0.6759 \\
\hline $\mathrm{D} \times .5+\mathrm{Dy} /(0-\mathrm{HN}$ & 3961 & 42 & & & & \\
\hline Dx $5+$ Dy $10-\mathrm{H} \mathrm{T}$ & 3504 & 45 & $<0.0()(0)$ & 0.1087 & & 0.0107 \\
\hline $\mathrm{B} 52 \mathrm{a}-6 \mathrm{~N}$ & 4090 & 37 & & & & \\
\hline$B 52 \mathrm{al}-6 \mathrm{~T}$ & 4119 & 34 & $<0.0001$ & 0.6897 & & \\
\hline \multicolumn{7}{|c|}{ Grain volume weight $(\mathrm{kg} / \mathrm{hL}$ ) } \\
\hline Controls & 78.5 & 2.9 & & & & \\
\hline Dy IOE N & 76.4 & 3.8 & & & & \\
\hline DyloE T & 75.8 & 3.3 & $<0.0001$ & 0.0181 & 0.1039 & 0.3000 \\
\hline Dx $5+$ Dy $10-\mathrm{H} \mathrm{N}$ & 77.5 & 2.3 & & & & \\
\hline $\mathrm{D} \times 5+\mathrm{Dy} 10-\mathrm{H} \mathrm{T}$ & 76.4 & 3.2 & $<0.0001$ & 0.0147 & & 0.0260 \\
\hline$B 52 a-6 \mathrm{~N}$ & 77.7 & 2.3 & & & & \\
\hline B52a-6 T & 75.5 & 2.6 & $<0.0001$ & $<.0001$ & & \\
\hline \multicolumn{7}{|c|}{ Single kernel weight (g) } \\
\hline Controls & 30.7 & 9.7 & & & & \\
\hline Dy lOE N & 31.2 & 8.5 & & & & \\
\hline DyloE T & 31.8 & 8.7 & 0.0202 & 0.363 & $<0.000)$ & 0.005 \\
\hline $\mathrm{D} \times 5+\mathrm{D} y 10-\mathrm{H} \mathrm{N}$ & 33.5 & 9.7 & & & & \\
\hline $\mathrm{D} \times 5+\mathrm{D}$ y $10-\mathrm{HT}$ & 34.9 & 11.1 & $<0.00001$ & 0.0227 & & $<0.0001$ \\
\hline$B 52 a-6 N$ & 31.8 & 9.0 & & & & \\
\hline$B .52 a-6 T$ & 30.1 & 9.7 & 0.2702 & 0.0011 & & \\
\hline \multicolumn{7}{|c|}{ Single kernel hardness (units) } \\
\hline Controls & 62.1 & 16.9 & & & & \\
\hline Dy 10 E N & 57.0 & 14.9 & & & & \\
\hline Dy I0E T & 61.5 & 16.9 & 0.8231 & 0.0002 & $<0.0001$ & 0.276 .3 \\
\hline Dx $5+$ Dy $10-\mathrm{H} \mathrm{N}$ & 58.3 & 14.1 & & & & \\
\hline $\mathrm{D} \times 5+\mathrm{D} y 10-\mathrm{H} \mathrm{T}$ & 68.6 & 15.8 & $<0.00001$ & $<.0001$ & & $<0.0001$ \\
\hline$B 52 a-6 N$ & 58.8 & 15.7 & & & & \\
\hline$B 52 \mathrm{a}-6 \mathrm{~T}$ & 60.3 & 20.3 & 0.2002 & 0.2412 & & \\
\hline \multicolumn{7}{|c|}{ Grain protein $(14 \% \mathrm{mb})$} \\
\hline Controls & 12.8 & 10.78 & & & & \\
\hline Dy $10 \mathrm{E} N$ & 1.3 .5 & 10.61 & & & & \\
\hline Dy $10 \mathrm{E} T$ & 13.3 & 10.62 & 0.0161 & 0.4441 & 0.0321 & 0.2228 \\
\hline $\mathrm{D} \times 5+\mathrm{Dy} 10-\mathrm{H} \mathrm{N}$ & 13.6 & 8.868 & & & & \\
\hline Dx $5+D$ y $10-\mathrm{HT}^{\mathrm{T}}$ & 13.8 & 7.325 & 0.0001 & 0.2567 & & 0.3682 \\
\hline$B 52 a-6 N$ & 13.6 & 9.959 & & & & \\
\hline B52a-6T & 13.6 & 10.32 & 0.0021 & 0.8833 & & \\
\hline
\end{tabular}

a $P$ values for contrasts of transgenic genotypes vs. controls, transgenic genotypes vs. nontransgenic siblings. and transgenic genolypes vs. each other only. 
those derived from events such as Dy 10-E and Dx5+Dy10-H, is so great, that effective mixing of protein and starch particles is prohibited. Attainment of a mixograph peak might be precluded by the presence of an abnormally tight protein network that may, in turn, prevent samples from absorbing water, reaching hydration, and displaying any increase in resistance to mixing.

Mixograph tolerance scores also varied among the transgenic events. Dx $5+$ Dy $10-\mathrm{H}$ was excluded from calculation of contrasts, again due to the low frequency of samples with detectable peak times. Events Dyl(0-E and B52a-6 typically produced lines with mixograms with acceptable tolerance scores, and those of B52a-6 lines did not differ from the mean of the controls (Table II).

Bake mix times of all three transgenic treatments were statistically greater than the controls and the nontransgenic siblings (Table III), and the mean of treatment Dyl0-E exceeded the mean of the two additional transgenic treatments. Loaf volumes of all three transgenic events were depressed (Table II), and all were significantly lower than both the means of the controls and the nontransgenic siblings. B52a-6 loaf volumes were significantly greater than those of both Dyl()-E and Dx5+Dy 10-H lines but still were significantly lower than the controls (Table III). Average loaf volumes of all three transgenic treatments were below the commercially acceptable loaf volume target of $900 \mathrm{~mL}$ (USDA 2006).

Farinograph behavior also was variable (Table III; Fig. 3). Dx5+ Dy $10-\mathrm{H}$ lines had a mean farinograph peak time of only $1.7 \mathrm{~min}$. This behavior was akin to mixograph behavior of these lines. There was some limited initial water absorption but additional mixing and absorption were prevented by the extremely tight protein matrix. Event Dy 10 -E produced mean farinograph peak times that did not differ from the control mean. B52a-6 derivatives had very long farinograph peak times that were significantly grcater than the mean of the controls, the two additional transgenic treatments, and the mean of its respective transgenic siblings. Farinograph stability also differed among the transgenic treatments. Stability of Dy 10-E was significantly less than both the controls and its transgenic siblings, but at a mean of 12.3 min was $6 x$ greater than the mean of Dx5+Dy10-H. Dx5+Dy $10-\mathrm{H}$ averaged stability of only $2.2 \mathrm{~min}$; in contrast, its nontransgenic siblings. averaged $18.2 \mathrm{~min}$. Again, this behavior does not indicate a weak dough, but rather an abnormal one that fails to mix properly.

TABLE II

Mean Values and Statistical Contrasts for Flour Quality Traits, Transgenic Lines (T), Nontransgenic Siblings (N), and Control Cultivars, 2005-2007, Mead, NE

\begin{tabular}{|c|c|c|c|c|c|c|}
\hline \multirow[b]{2}{*}{ Treatment } & \multirow[b]{2}{*}{ Flour protein $(14 \% \mathrm{mb})$} & \multicolumn{5}{|c|}{ Contrasts $^{\mathrm{it}}$} \\
\hline & & $\operatorname{CV}(\%)$ & Controls & Nontransgenic Siblings & Dx5+Dy 10-H T & B52T \\
\hline Controls & 11.5 & 11.4 & & & & \\
\hline Dy $10 \mathrm{EN}$ & 12.1 & 11.7 & & & & \\
\hline Dy10E T & 12.2 & 11.3 & 0.001 & 0.5188 & 0.2667 & 0.1894 \\
\hline $\mathrm{D} \times 5+\mathrm{D}$ y $10-\mathrm{H} \mathrm{N}$ & 12.0 & 8.4 & & & & \\
\hline $\mathrm{D} \times 5+\mathrm{Dy} 10 \times \mathrm{H} \mathrm{T}$ & 12.4 & 7.2 & 0.0006 & 0.1177 & & 0.9409 \\
\hline$B 52 a-6 N$ & 12.3 & 10.0 & & & & \\
\hline \multirow[t]{2}{*}{ B52a-6 T } & 12.5 & 9.5 & 0.0001 & 0.4902 & & \\
\hline & Flour extraction ( $\%$ ) & & & & & \\
\hline Controls & 71.8 & 3.1 & & & & \\
\hline DyloEN & 71.6 & 3.5 & & & & \\
\hline DyloE T & 71.2 & 3.9 & 0.0802 & 0.7699 & $<0.0001$ & $<0.00001$ \\
\hline $\mathrm{D} \times 5+\mathrm{Dy} 10-\mathrm{H} \mathrm{N}$ & 71.6 & 3.8 & & & & \\
\hline Dx $5+$ Dyl0-H T & 68.5 & 5.7 & $<0.0001$ & $<0.0(0) 1$ & & 0.069 \\
\hline$B 52 a-6 N$ & 70.0 & 4.9 & & & & \\
\hline \multirow[t]{2}{*}{ B52a-6 T } & 69.1 & 5.6 & $<0.0001$ & 0.1244 & & \\
\hline & Flour ash $(14 \% \mathrm{mb})$ & & & & & \\
\hline Controls & 0.44 & 17.1 & & & & \\
\hline DyloE $\mathrm{N}$ & 0.46 & 18.4 & & & & \\
\hline DyloE T & 0.47 & 16.5 & $<0.000)$ & 0.0026 & $<0.0001$ & 0.0028 \\
\hline Dx $5+\mathrm{Dy} 10-\mathrm{HN}$ & 0.42 & 13.1 & & & & \\
\hline Dx $5+$ Dy $10-H T$ & 0.52 & 11.9 & $<0.00001$ & $<0.0001$ & & $<0.00001$ \\
\hline B $52 a-6 \mathrm{~N}$ & 0.43 & 14.9 & & & & \\
\hline \multirow[t]{2}{*}{ B52a-6 T } & 0.44 & 12.6 & 0.6581 & 0.0097 & & \\
\hline & ixograph time to peak (m & & & & & \\
\hline Controls & 4.3 & 300 & & & & \\
\hline Dy IOE N & 9.2 & 125.6 & & & & \\
\hline DyloE T & 40.1 & 45.1 & $<0.0001$ & $<0.0001$ & nd & $<0.0(00)$ \\
\hline $\mathrm{D} \times 5+\mathrm{D} y 10-\mathrm{H} \mathrm{N}$ & 5.08 & 20.4 & & & & \\
\hline $\mathrm{D} \times 5+$ Dyl0-H T & $n \mathrm{~d}^{\mathrm{h}}$ & nd & nd & nd & & nd \\
\hline B $52 a-6 N$ & 4.9 & 17.9 & & & & \\
\hline \multirow[t]{2}{*}{$B 52 a-6 T$} & 17.4 & 46.4 & $<0.00001$ & $<0.000)]$ & & \\
\hline & lixograph tolerance (0-6) & & & & & \\
\hline Controls & 3.6 & 38.3 & & & & \\
\hline Dyloti $N$ & 3.4 & 33.3 & & & & \\
\hline DyloE T & 3.8 & 41.9 & 0.03 & 0.005 & nd & 0.09 \\
\hline Dx.5+Dy $10-\mathrm{H} \mathrm{N}$ & 3.0 & 48.3 & & & & \\
\hline Dx.5+Dyl0-H T & $\mathrm{nd}$ & nd & nd & nd & & nd \\
\hline B52ai-6 N & 3.4 & 36.7 & & & & \\
\hline $\mathrm{B} 52 \mathrm{a}-6 \mathrm{~T}$ & 3.6 & 48.7 & 0.9981 & 0.4548 & & \\
\hline
\end{tabular}

" $P$ values for contrasts of transgenic genotypes vs. controls, transgenic genotypes vs, nontransgenic siblings, and transgenic genotypes vs. each other only.

Not determined. See text for details. 


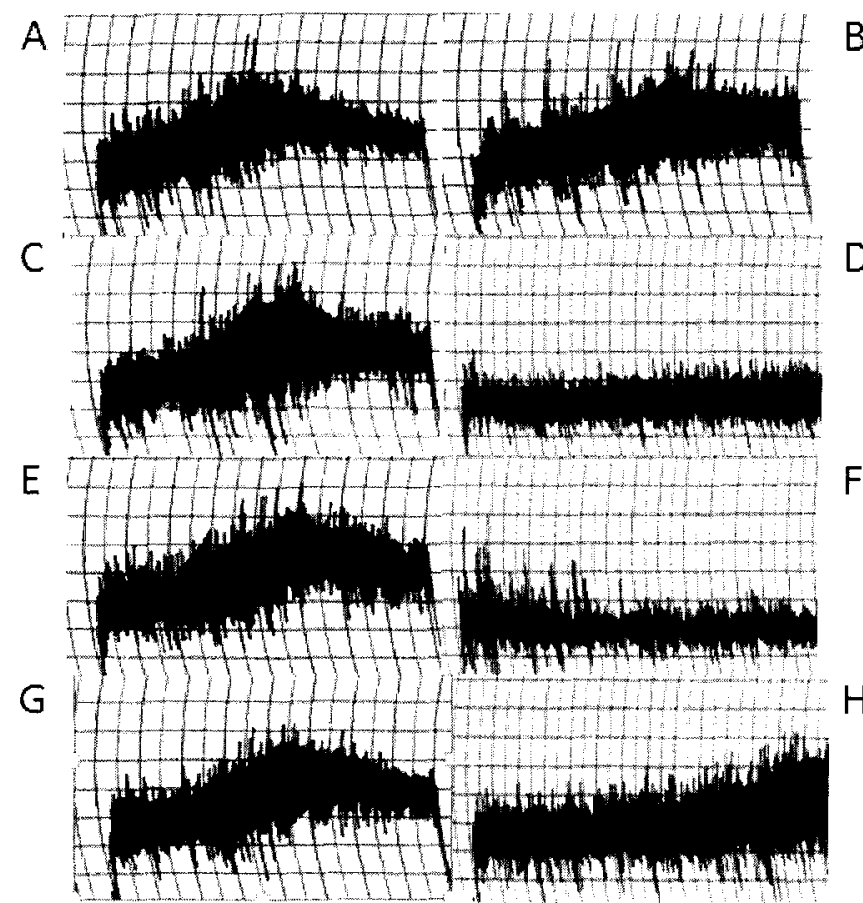

Fig. 2. Representative mixograms from samples of the 2007 harvest year. $\mathrm{A}=$ Trego, $\mathrm{B}=$ Anton, $\mathrm{C}=\mathrm{Dy}-10-\mathrm{E}$ nontransgenic sib. $\mathrm{D}=\mathrm{Dy} 10$-E trans genic, $\mathrm{E}=\mathrm{D} \times 5+\mathrm{Dy} 10-\mathrm{H}$ nontransgenic sib $F=\mathrm{D} \times 5+\mathrm{Dy} 10-\mathrm{H}$ transgenic $\mathrm{G}=\mathrm{B} 52 \mathrm{a}-6$ nontransgenic sib. $\mathrm{H}=\mathrm{B} 52 \mathrm{a}-6$ transgenic.

Farinograph stability of B52a-6 was significantly longer than that of all compared treatments. Observations differed for farinograph tolerance index (MTI), with Dyl0-E and Dx5+Dyl0-H having significantly greater scores than B52a-6, the controls, and the nontransgenic siblings. B52a-6 lines did not differ from either the controls or the transgenic siblings.

Regarding the environmental stability of measured traits, all transgenic and nontransgenic groups displayed greater variability in grain yield over years, as indicated by higher $\mathrm{CV}$ values than the controls (Table I). CV values of the transgenic lines associated with additional grain quality traits (grain volume weight, grain hardness. and grain protein concentration) were of a similar magnitude to those of the controls and nontransgenic siblings, indicating a similar level of stability. For dough mixing traits (mixograph and farinograph parameters, and loaf volumes) $C V$ values in the transgenic materials often were elevated relative to the other treatments (Tables II and III). The elevated $\mathrm{CV}$ values for these traits might not derive from a lack of environmental stability but rather the marked changes in the mixing properties of the doughs often rendered it difficult to detect the peak mixing times. Consequently, this could translate to elevated variation in loaf volumes, as doughs that are overmixed or undermixed will not bake properly. In extreme perturbation of mixing, observed with Dx5+ Dy $10-\mathrm{H}$, breadmaking properties elfectively were eliminated.

The genetic effects of event Dy $10-E$ in hard winter wheat backgrounds can be compared to those described previously for this event in the original recipient spring wheat cultivar Bobwhite (Bregitzer et al 2006; Blechl el al 2007). (B52a-6 and Dx5+Dy 10$H$ were not included in those studies). In the previous field trial study (Bregitzer et al 2006), Dy 10-E had average yields that did not differ from its nontransgenic parent Bobwhite at the two California locations or at the Idaho site. In contrast, results presented here show that the transgene locus had a marginally significantly positive effect on average yield in the winter wheat backgrounds. where the appropriate comparison is to the average yields of its nontransgenic siblings (Table I). Transgenic lines derived from Dy 10-E actually displayed higher mean grain yields than the non-
A
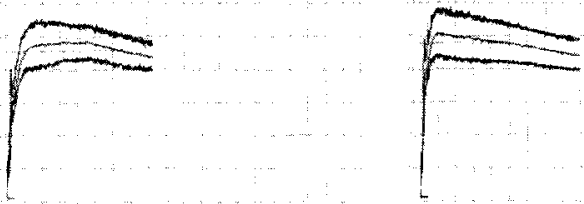

B

C
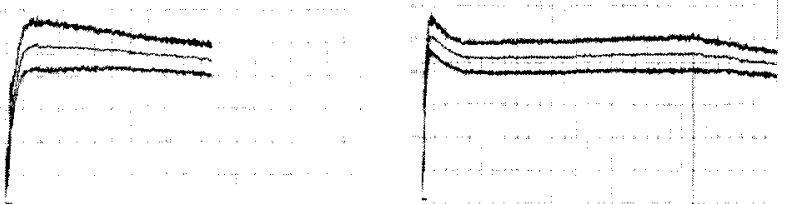

E

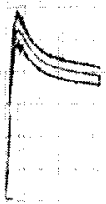

$\mathrm{F}$

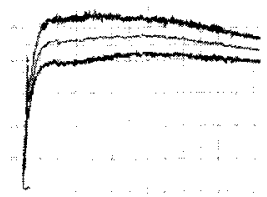

G
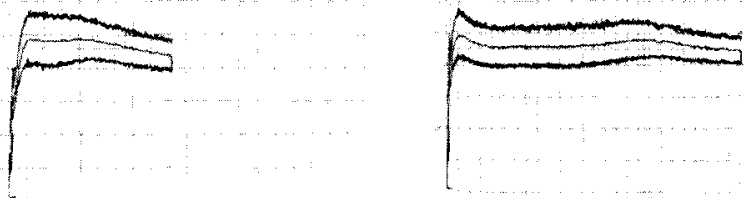

$\mathrm{H}$

Fig. 3. Representative farinograms from samples of the 2007 harvest year $\mathrm{A}=$ Trego. $\mathrm{B}=$ Anton. $\mathrm{C}=\mathrm{Dy}-\mathrm{I0}-\mathrm{E}$ nontransgenic sib. $\mathrm{D}=\mathrm{Dy} \mathrm{I}(\mathrm{O}-\mathrm{E}$ transgenic, $E=D \times 5+D y 10-\mathrm{H}$ nontransgenic sib, $F=D \times 5+D y 10-\mathrm{H}$ transgenic, $\mathrm{G}=$ B52a-6 nontransgenic sib. $\mathrm{H}=\mathrm{B} 52 \mathrm{a}-6$ transgenic. Farinograms from the same samples as Fig. 2. $X$ axis = time in minutes; $Y$ axis $=$ Brabender Units.

transgenic siblings, although yields were depressed relative to the controls. As noted above. only two backcrosses to winter wheats were performed in deriving the lines in this study. The lower yields relative to the control cultivars likely arose from the lack of sufficient genetic material for adaptation to the Nebraska winter wheat environment. No differences were noted in the original IDy-10 event test weight. 100-kernel weight, or grain protein compared to Bobwhite over two years in the spring wheat study (Bregitzer et al 2006). This is in agreement with the lack of differences for single kernel weight and grain protein in winter wheat derivatives of Dy 10-E (Table I). Mixograph tests (2-g) conducted on original event Dylo-E had peak times just before $50 \mathrm{~min}$ of mixing (Blechl et al 2007). This is the maximum run time for the 2 -g instrument, thus mixing tolerance could be not be determined for Dy $10-E$ in those studies.

These extra strong mixing characteristics are also seen in the more standard $10 \mathrm{~g}$ mixograph and farinograph tests conducted on the winter wheat derivatives of this event (Tables II and III) Overall, the results indicate that the mixing behavior attributable to the transgene locus is highly heritable.

In previous investigations (Vasil et al 2001: Rakszegi et al 2005. 2008: Blechl et al 2007: Field et al 2008; Wang et al 2010), the effects of additional copies of HMW-GS $1 \mathrm{Ax} 1$ tended to be more benign than those of IDyl0, which, in turn, tended to be less drastic than those of IDx5. In the present investigation, B52a-6 overexpressing HMW-GS 1Dyl0 had less dramatic effects than other events investigated. Pierucci et al (2009) made similar observations with B52a-6 and tortilla properties. Their results were attributed to a lower increase in the glutenin-to-gliadin ratio in B52a-6 lines. The results of the present investigation confirm the 
TABLE III

Mean Values and Statistical Contrasts for Baking and Farinograph Properties, Transgenic Lines (T), Nontransgenic Siblings (N), and Control Cultivars, 2005-2007, Mead, NE

\begin{tabular}{|c|c|c|c|c|c|c|}
\hline \multirow[b]{2}{*}{ Treatment } & \multirow[b]{2}{*}{ Bake mix time (min) } & \multicolumn{5}{|c|}{ Contrasts $^{a}$} \\
\hline & & $\mathrm{CV}(\%)$ & Controls & Nontransgenic Siblings & Dx $5+$ Dy $10-H ~ T$ & B52a-6 T \\
\hline Controls & 5.88 & 30.2 & & & & \\
\hline DyloE N & 9.8 & 96.5 & & & & \\
\hline Dy loE T & 22.4 & 84.5 & $<0.0001$ & $<0.0001$ & $<0.0001$ & 0.0008 \\
\hline Dx5+Dyl0-H N & 6.3 & 21.2 & & & & \\
\hline $\mathrm{D} \times 5+\mathrm{Dy}] 0-\mathrm{H} \mathrm{T}$ & 12.0 & 37.2 & 0.0029 & 0.0147 & & 0.0562 \\
\hline$B 52 a-6 N$ & 0.11 & 21.2 & & & & \\
\hline$B 52 \mathrm{a}-6 \mathrm{~T}$ & 16.2 & 42.2 & $<0.000) 1$ & $<0.0001$ & & \\
\hline \multicolumn{7}{|c|}{ Loaf volume ( $\mathrm{mL}$ ) } \\
\hline Controls & 878 & 9.6 & & & & \\
\hline Dy IOE N & 881 & 9.9 & & & & \\
\hline DyIOE T & 528 & 24.9 & $<0.0001$ & $<0.000)$ & $<0.0001$ & $<0.0001$ \\
\hline Dx.5+Dy $10-\mathrm{H} \mathrm{N}$ & 891 & 7.7 & & & & \\
\hline D $\times 5+$ Dy $10-\mathrm{HT}$ & 355 & 43.2 & $<0.0001$ & $<0.0001$ & & $<0.0001$ \\
\hline B52a-6 N & 891 & 7.5 & & & & \\
\hline$B 52 \mathrm{a}-6 \mathrm{~T}$ & 701 & 15.3 & $<0.0001$ & $<0.0001$ & & \\
\hline \multicolumn{7}{|c|}{ Farinograph peak time (min) } \\
\hline Controls & 7.9 & 84.4 & & & & \\
\hline DyloE N & 12.6 & 106.7 & & & & \\
\hline DyloE T & 7.9 & 199.3 & 0.9133 & 0.0253 & 0.0157 & $<0.0001$ \\
\hline Dx $5+$ Dy $10-\mathrm{H} \mathrm{N}$ & 9.6 & 60.8 & & & & \\
\hline $\mathrm{D} \times 5+\mathrm{D} y 10-\mathrm{H} \mathrm{T}$ & 1.7 & 13.5 & 0.0112 & 0.0038 & & $<0.0001$ \\
\hline$B 52 a-6 N$ & 9.9 & 43.4 & & & & \\
\hline $\mathrm{B} 52 \mathrm{a}-6 \mathrm{~T}$ & 27.7 & 73.2 & $<0.0001$ & $<0.0001$ & & \\
\hline \multicolumn{7}{|c|}{ Farinograph stability (min) } \\
\hline Controls & 16.6 & 49.9 & & & & \\
\hline DyloE N & 22.1 & 62.6 & & & & \\
\hline DyloE $T$ & 12.3 & 155.4 & 0.0139 & $<0.0001$ & 0.0005 & $<0.0001$ \\
\hline Dx5+Dy $10-\mathrm{H} \mathrm{N}$ & 18.2 & 35.5 & & & & \\
\hline $\mathrm{D} \times 5+\mathrm{D}$ y $10-\mathrm{H}^{\mathrm{T}}$ & 2.2 & 94.4 & $<0.0001$ & $<0.0001$ & & $<0.0001$ \\
\hline $\mathrm{B} 52 \mathrm{a}-6 \mathrm{~N}$ & 18.1 & 29.8 & & & & \\
\hline B52a-6 T & 32.5 & 59.5 & $<0.0001$ & $<0.0001$ & & \\
\hline \multicolumn{7}{|c|}{ Farinograph tolerance index (MTI) } \\
\hline Controls & 23.9 & 58.1 & & & & \\
\hline DyloE N & 21.5 & 71.8 & & & & \\
\hline DyloE T & 51.9 & 58.0 & $<0.0001$ & $<0.0001$ & $<0.0001$ & $<0.0001$ \\
\hline Dx $5+$ Dy $10-H \mathrm{~N}$ & 22.3 & 63.3 & & & & \\
\hline Dx $5+$ Dy $10-H T$ & 81.5 & 37.2 & $<0.0001$ & $<0.0001$ & & $<0.0001$ \\
\hline B52a-6 N & 20.2 & 66.7 & & & & \\
\hline $\mathrm{B} 52 \mathrm{a}-6 \mathrm{~T}$ & 18.8 & 83.4 & 0.1933 & 0.6479 & & \\
\hline
\end{tabular}

" $P$ values for contrasts of transgenic genotypes vs. controls, transgenic genotypes vs. nontransgenic siblings, and transgenic genotypes vs. each other only.

unique properties of B52a-6 derivatives. This could simply be a quantitative effect in that the amount of 1 Dy 10 overexpression in B52-6a is lower than that in Dy 10-E lines (lanes 4 and 6, respectively in Fig. 1) (Pierucci et al 2009). In addition to overexpressing HMW-GS 10, B52a-6 produces two novel HMW-GS that migrate (SDS-PAGE) in the region between HMW-GS Dx5 and $\mathrm{Bx} 7$ (Fig. 1). It is possible these two novel proteins temper the effects of overexpression of 1Dy 10 on dough properties and that the production of novel HMW-GS, perhaps due to rearranged genes generated during the transformation process, might serve as a new tool for the generation of useful genetic variation in wheat. Dx $5+$ Dy $10-\mathrm{H}$ lines also produce a novel protein that migrated with a higher apparent molecular weight than HMW-GS IAx2*. Because this protein is a variant of 1Dx5 (A. E. Blechl, personal communication), it is not surprising that it did little to temper or alter the effects of overexpression of native HMW-GS 5. Mixing traces indicative of inadequate hydration and mixing were observed; such doughs are unlikely to be commercially useful.

HMW-GS IDy 10 , along with the genetically linked HMW-GS 1Dx5, have long been considered the most important and most effective glutenin subunits in terms of potential impact on bread- making quality (Payne 1987). Overexpression of beneficial HMWGS seemed an entirely logical approach to the improvement of wheat quality. This investigation and many of the previous experiments cited above that manipulated the amount of these subunits often resulted in perhaps "too much of a good thing" and overly strong doughs were the result. Future experiments designed to temper the levels of expression of HMW-GS 1Dy 10 might result in improved breadmaking quality. While B52a-6 derivatives produce doughs that are too strong alone, they might have potential as blending wheats to improve the quality of weak doughs or in products such as whole wheat breads requiring stronger gluten.

\section{ACKNOWLEDGMENTS}

We wish to acknowledge the technical assistance of Vern Hansen, Lori Divis. T. J. McAndrew. Margo Caley, and Laura McLaughlin.

\section{LITERATURE CITED}

AACC International. 2010. Approved Methods of Analysis, 11th Ed Available online only. AACC International: St. Paul, MN.

Altpeter, F., Vasil, V., Srivastava, V., Stoeger, E., and Vasil, I. K. 1996 
Accelerated production of transgenic wheat (Triticam astiram L.) plants. Plant Cell Rep. 16:12-17.

Altpeter, F.. Baisakh, N.. Beachy, R., Bock. R., Capell, T., Christou, P. Daniell. H.. Datta, K., Datta, S.. Dix, P. J., Fatuquet, C., Huang, N.. Kohli, A., Mooibroek, H.. Nicholson, L., Nguyen, T. T., Nugent, G. Raenakers, K., Romano, A., Somers, D. A.. Stoger, E.. Taylor, N., and Visser, R. 2005. Particle bombardment and the genetic enhancement of crops: Myths and realities. Molec. Breed. 15:305-327.

Alvarez, M. L., Guelman. S., Halford, N. G., Lusling, S., Reggiardo. M. I.. Ryboshkina, N.. Shewry, P.. Stein, J.. and Vallejos. R. H. 2000. Silencing of HMW glutenins in transgenic wheat expressing extra HMW subunits. Theor. Appl. Genet. 100:319-327.

Barro. F., Rooke. L., Bekes, F., Gras, P.. Tatham, A. S.. Fido. R., Lazzeri. P. A., Shewry, P. R., and Barcelo. P. 1997. Transformation of wheat with high molecular weight subunit genes results in improved functional properties. Nature Biotechnol. 15:1295-1299.

Barro. F., Barceló, P., Lazzeri, P. A.. Shewry, P. R., Martín, A.. and Ballesteros, J. 2002. Field evaluation and agronomic performance of transgenic wheat. Theor. Appl. Gene1. 105:980-984.

Blechl. A. E. and Anderson. O. D. 1996. The expression of a novel high-molecular-weight glutenin subunit gene in transgenic wheat. Nature Biotechnology 14:875-879.

Blechl, A. E., Le, H. Q., Békés, F., Gras, P. W., Shimon. Y.. Galili, G., and Anderson, O. D. 1997. Application of molecular biology in understanding and improving wheat quality. Pages 205-211 in: Proc. Int. Wheat Quality Conf. J. I. Steele and O. K. Chung, eds. GIA: Manhattan. KS.

Blechl A. E., Lin, J., Nguyen, S., Chan, R.. Anderson, O. D., and Dupont. F. M. 2007. Transgenic wheats with elevated levels of $1 \mathrm{D} \times 5$ and/or 1Dy10 high-molecular-weight glutenin subunits yield doughs with increased mixing strength and tolerance. J. Cereal Sci. 45:172-183.

Bregitzer, P., Blechl, A. E., Fiedler, D., Lin, J., Sebesta, P., De Soto, J. F. Chicaiza, O., and Dubcovsky. J. 2006. Changes in high molecular weight glutenin subunit composition can be genetically engineered without affecting wheat agronomic performance. Crop Sci. 46:1553-1563.

Chen, H.. Bodulovic, G., Hall, P. J., Moore, A.. Higgins. T. J. V., Djordjevic. M. A., and Rolfe. B. G. 2009. Unintended changes in protein expression revealed by proteomic analysis of seeds from transgenic pea expressing a bean $\alpha$-amylase inhibitor gene. Proteomics 9:4406-4415.

Darlington. H., Fido. R.. Tatham. A. S.. Jones. H.. Salmon. S. E.. and Shewry, P. R. 2(0)3. Milling and baking propertics of field grown wheat expressing HMW subunit transgenes. J. Cereal Sci. 38:301-306.

Di Luccia. A., Lamacchia, C., Fares, C., Padalino, L.. Mamone, G., La Gatta, B., Gambacorta, G., Faccia, M., Di Fonzo, N., and La Notte. E. 2005. A proteomic approach to study protein variation in GM durum wheat in relation to lechnological properties of semolina. Annal. Chim. 95:405-414.

Field. J. M.. Bhandari. D.. Bonet. A.. Underwood. C.. Darlington. H.. and Shewry. P. 2008. Introgression of transgenes into a commercial cultivar confirms differential effects of HMW subunits $1 \mathrm{Ax} /$ and IDx5 on gluten properties. J. Cereal Sci, 48:457-463.

Finnie. S. M., Jeannotte, R., Morris. C. F., and Faubion. J. M. 2010. Variation in polar lipid composition among near-isogenic wheat lines possessing different puroindoline haplotypes. J. Cereal Sci. 51:66-72.

Giuliano Albo. A., Mila, S.. Digilio. A. G., Moto. M., Aime. S., and Corpillo, D. 2007. Proteomic analysis of a genetically moditied maize thour carrying Cry $1 \mathrm{Ab}$ gene and comparison to the corresponding wildtype. Maydica 52:443-455.

Greenwell. P., and Schofield. J. D. 1986. A starch granule protein associated with endosperm softness in wheat. Cereal Chem. 63:379-380.

He, G. Y., Jones, H. D., D'Ovidio, R., Masei, S., Chen, M. J., West, J., Butow, B.. Anderson. O. D.. Lazzeri, P., Fido, R., and Shewry, P. R. 2005. Expression of an extended HMW subunit in transgenic wheat and the effect on dough mixing properties. J. Cereal Sci. 42:225-231.

León, E.. Marín. S., Giménez. M. J.. Pision. F., Rodrígucz-Quijano. M., Shewry, P. R., and Barro, F. 2009. Mixing properties and dough functionality of transgenic lines of a commercial wheat cultivar expressing the 1Axl, 1Dx5 and IDyl0 HMW glutenin subunit genes. J. Cereal Sci. 49:148-156

Masci, S.. D Ovidio. R. Scossa, F.. Patacchini, C., Lafiandra, D.. Anderson. O. D., and Blechl, A. E. 2003. Production and characterization of a transigenic bread wheat line over-expressing a low-molecular-weight glutenin subunit gene. Molec. Breed. 12:209-222.

Mehlo, L., Marithuleki, G., Twyman. R. M., Boulton. M. I., Ditvies, J. W., and Christou. P. 2000. Struetural analysis of transgene rearrangements and effects on expression in transgenic maize plants generated by particle bombardment. Maydica 45:277-287.

Payne. P. I. 1987. Genetics of wheat storage proteins and the effect of allelic variation on bread-making quality. Ann. Rev. Plant Physiol. 38:I4I-153.

Pierucci, V. R. M., Tilley. M., Graybosch, R. A., Blechl. A. E.. Bean, S. R., and Tilley. K. A. 2009. Effects of overexpression of high molecular weight glutenin subunit Dy 10 on wheat tortilla properties. J. Agric. Food Chem. 57:6318-6.326.

Purdy, L. H., Loegerin. W. Q., Konzak, C. F., Peterson, C. J., and Allan, R. E. 1968. A proposed standard method for illustrating pedigrees of small grain varieties. Crop Sci. 8:405-406.

Rakszegi. M., Békés. F.. Láng, L., Tamás, L., Shewry, P. R., and Bedö. Z. 2005. Technological quality of transgenic wheat expressing an increased amount of a HMW glutenin subunit. J. Cereal Sci. 42:15-32.

Rakszegi, M., Pastori, G., Jones, H. D., Békés, F., Butow, B., Láng, L., Bedö, Z., and Shewry, P. R. 2008. Technological quality of held grown transgenic lines of conmercial wheat cultivars expressing the $\mid \mathrm{Ax} I$ HMW glutenin subunit gene. J. Cereal Sci. 47:310-321

Ruebelt, M. C.. Lipp, M.. Reynolds, T. L., Schmuke, J. J., Astwood, J. D., Dellatennia, D., Engel, K.-H., and Jany, K.-D. 2006 . Application of twodimensional gel electrophoresis to interrogate alterations in the proteome of gentically modified crops. 3. Assessing unintended effects. J. Agric. Food Chem. 54:2169-2177.

Scossa, F., Laudencia-Chingcuanco, D., Anderson, O. D., Vensel, W. H., Laffiandra, D., D Ovidio. R., and Masci, S. 2008. Comparative proteomic and transcriptional profiling of a bread wheal cultivar and its derived transgenic line overexpressing a low molecular weight glutenin subunit gene in the endospern. Proteomics 8:2948-2966.

Shewry. P. R.. Miles, M. J., and Tatham. A. S. 1994. The prolamin storage proteins of wheat and related cereals. Progr. Biophysics Molec. Biol. 61:37-59.

Shewry. P. R., Powers. S., Field, J. M.. Fido, R. J.. Jones, H. D.. Arnold. G. M., West. J.. Paul. A.. Larzeri, P. A., Barcelo, P. Barro, F., Tatham. A. S., Bekes, F., Butow, B., and Darlington, H. 2006. Comparative field pertormance over 3 years and two sites of transgenic wheat lines expressing HMW subunit transgenes. Theor. Appl. Genet. 113:128-136.

Shimoni, Y., Blechl, A. E., Anderson, O. D., and Galili, G. 1997. Recombinant protein of two high molecular weight glutenins alters gluten polymer formation in transqenic wheat. J. Biol. Chem. 272:15488-15495.

Stenvert. N. L.. and Kingswood, K. 1977. Influence of the physical structure of the protein matrix on wheat hardness. J. Sci. Food Agric. 28: I I19.

USDA. 2006 . Recommended quality tareets for hard red winter wheat. Online at http:/Www.ars.usda.gov/SP2UserFiles/Place/54300510/ StatementofPurposeHardWinter WheatRecommendedQualityTargets(rev2-2 I (07).pdf.

Vasil, V.. Castillo. A. M.. Fromm. M. E.. and Vasil, I. K. 1992. Herbicide resistant fertile transgenic wheat plants obtained by microprojectile bombardment of regenerable embryogenic callus. BioTechnol. 10:667-674.

Vasil, I. K., Bean, S., Zhao, J., McCluskey, P., Lookhart, G., Zhao, H. P., Altpeter, F.. and Vasil. V. T. I. 2001. Evaluation of baking properties and gluten protein composition of field grown transgenic wheal lines expressing high molecular weight glutenin gene $1 \mathrm{Ax}$ 1. J. Plant Physiol. 1.58:521-528.

Wang, Y., Li, Y., Zhang, L.. Gao, X., Miao, Y., Wang, C., Yang, G., Shewry, P. R., and He, G. 2010. Expression of the IAxl transgene in an elite Chinesi wheat variety and its effect on functional properties. J. Sci. Food Agric 90:106-111.

Weegels. P. L.. Hamer. R. J.. and Schofield, J. D. 1996. Functional properties of wheat glutenin. J. Cereal Sci. 23:1-18

Wecks, J. T. Anderson, O. D., and Blechl, A. E. 1993. Rapid production of multiple independent lines of fertile transgenic wheat (Triticum aestivum). Plant Physiol. 102:1077-1084.

Wrigley, C. W., Bekes, F., and Bushuk, W. 2006. Gluten: A balance of gliadin and glutenin. Pages 3-34, in: Gliadin and Glutenin. The Unique Balance of Wheat Quality. C. Wrigley. F. Bekes, and W. Bushuk, eds. AACC International. St. Paul, MN. 